\title{
IMPLEMENTASI PERATURAN DAERAH KABUPATEN BADUNG NOMOR 10 TAHUN 2017 TENTANG KAWASAN TANPA ROKOK PADA TEMPAT WISATA
}

\author{
Karinka, I Ketut Sukadana, I Nyoman Sutama \\ Fakultas Hukum Universitas Warmadewa, Denpasar - Bali, Indonesia
}

\begin{abstract}
Abstrak
Merokok adalah hak semua orang, namun merokok dapat menggangu Hak Asasi Manusia karena sebaran asap rokok yang dihasilkan oleh perokok dapat mengganggu kesehatan orang sekitar. Di Bali, tempat wisata termasuk salah satu kawasan tanpa rokok. Hal ini tercantum dalam Peraturan daerah kabupaten Badung Nomor 10 Tahun 2017 tentang Kawasan Tanpa Rokok. Terkait hal ini, penelitian menelaah dua hal, yakni pengaturan Kawasan Tanpa Rokok pada tempat wisata di Kabupaten Badung dan implementasi Peraturan Daerah Kabupaten Badung Nomor 10 Tahun 2017 terhadap tempat wisata dimaksud. Adapun metode penelitian yang digunakan adalah penelitian hukum empiris, yaitu, melakukan penelitian secara langsung yang dilanjutkan dengan menganalisis data dan disajikan secara kualitatif. Dalam pengaturannya, Satpol PP selaku penegak peraturan daerah telah melakukan pengawasan pada tempat wisata dan sanksi yang diberikan sesuai dengan Pasal 21 Nomor 102017 Peraturan Daerah Kabupaten Badung. Penerapannya telah dilakukan melalui sosialisasi kepada pengelola tempat wisata namun kurangnya pengetahuan masyarakat tentang kawasan tanpa rokok pada tempat wisata menjadi faktor penghambat.
\end{abstract}

Kata Kunci: Implementasi; Kawasan Tanpa Rokok; Tempat Wisata

\begin{abstract}
Smoking belongs to the right of all people, but smoking can interfere with Human Rights because the distribution of cigarette smoke produced by smokers can interfere with the health of people around. In Bali, tourist attractions are one of the non-smoking areas. This is stated in the Regional Regulation of Badung No. 10 of 2017 concerning NonSmoking Areas. Related to this, the study examines two things, that is, the regulation of No-Smoking Areas in the tourist attractions in Badung Regency and the implementation of the Regional Regulation of Badung No. 10 of 2017 on the tourist attractions. The research method used is empirical legal research that is conducting a direct research followed by analyzing data and presented in qualitative manner. In its regulation, Civil Service Police Unit (Satpol $P P)$ as the enforcer of the regional regulation has conducted supervision on tourist attractions and sanctions given in accordance with the Article 21 Number (10) of 2017 of the Badung Regency Regional Regulation. Its application has been done through socialization to the manager of tourist attractions, but the lack of public knowledge about the non-smoking areas in tourist attractions has been appearing as an inhibiting factor.
\end{abstract}

Keywords: Implementation; No-Smoking Area; Tourist attraction

\section{PENDAHULUAN}

Merokok telah menjadi kegiatan yang lumrah di kalangan masyarakat Indonesia. Merokok juga telah menjadi kebutuhan bagi mereka yang sudah kecanduan rokok (Priyangga, 2017: 4). Namun pada sisi efek negatifnya, merokok tidak hanya merugikan perokok tetapi juga orang disekitarnya (Juanita, 2012: 113). Pemerintah berusaha dalam meningkatkan kapasitas kesehatan masyarakat dengan membuat kebijakan tentang rokok.

Di dalam Peraturan Daerah Kabupaten Badung Nomor 10 Tahun 2017 tentang Kawasan Tanpa Rokok telah ditentukan area apa saja yang dikategorikan sebagai kawasan tanpa rokok. Seperti yang tercantum dalam Pasal 1 Angka 15 area yang dimaksud adalah tempat umum. Merujuk pada Peraturan 
Daerah sebelumnya nomor 8 Tahun 2013 tentang Kawasan Tanpa Rokok pada Pasal 10 huruf c yang dimaksud tempat umum ialah tempat wisata.

Kebijakan Kawasan Tanpa Rokok tersebut mempunyai maksud agar wisatawan mendapatkan haknya saat berwisata di lingkungan yang bersih tanpa khawatir akan paparan asap rokok disekitarnya. Dalam Pasal 13 Ayat (1) Peraturan Daerah Provinsi Bali Nomor 10 Tahun 2011 menyebutkan bahwa setiap orang dilarang merokok di kawasan Tanpa Rokok. Beberapa kajian tentang Kawasan Tanpa Rokok telah diluncurkan dengan metode ilmiah. Penelitian tentang KTR setidaknya telah dikaji dalam satu dekade terakhir. Beberapa kajian tersebut adalah seperti yang dilakukan oleh Juanita (2012), Solicha (2012), Azkha (2013), Priyangga (2017), Suryani \& Suhartini (2018), dan Marchel dkk. (2019). Namun implementasi Peraturan Daerah, khususnya daerah Badung Bali belum diteliti.

Berdasarkan latar belakang yang telah diuraikan, penelitian ini mengkaji dua pertanyaan: (1) Bagaimanakah pengaturan Kawasan Tanpa Rokok pada tempat wisata di Kabupaten Badung? (2) Bagaimanakah implementasi Peraturan Daerah Kabupaten Badung Nomor 10 Tahun 2017 pada tempat wisata?

\section{METODE PENELITIAN}

Tipe penelitian yang digunakan yaitu penelitian hukum empiris atau penelitian lapangan yaitu dengan menggunakan metode melalui fakta-fakta yang ditemukan dari perilaku manusia yang dilakukan saat pengamatan langsung dan wawancara. Sedangkan pendekatan penelitian ini ialah pendekatan kualitatif karena digunakan untuk memahami kejadian yang sedang terjadi di masyarakat. Sumber data yang digunakan yaitu data primer yaitu didapatkan dengan wawancara dengan informan dan data sekunder berupa peraturan perundang-undangan dan buku-buku lainnya. Adapun teknik pengumpulan data dilakukan melalui wawancara dengan Satpol PP selaku penegak peraturan daerah dan pengelola tempat wisata setempat. Saat semua data telah terkumpul lalu data akan diolah dengan menggunakan analisa kualitatif yaitu dengan menggabungkan data, lalu menjelaskannya dengan menghubungan dengan beberapa teori guna mendapatkan kesimpulan.

\section{HASIL PENELITIAN DAN PEMBAHASAN}

\section{Pengaturan Kawasan tanpa Rokok Nomor 10 Tahun 2017 Di Kabupaten Badung}

Rokok termasuk dalam salah satu masalah yang belum bisa ditangani oleh pemerintah dan pemerintah mempunyai tanggung jawab dalam meningkatkan kesehatan masyarakat. Sesuai kebijakan yang tercantum dalam Undang-Undang Nomor 36 Tahun 2009 tentang Kesehatan pada Pasal 115 Ayat (2) Pemerintah Daerah wajib mengatur Kawasan Tanpa Rokok di daerahnya. Dengan ini Pemerintah Daerah Kabupaten Badung mengeluarkan Peraturan Daerah Kabupaten Badung Nomor 8 tahun 2013 yang kemudian di revisi menjadi Peraturan Daerah Kabupaten BadungNomor 10 Tahun 2017.

Dalam pengaturannya area kawasan Tanpa Rokok yakni: tempat pelayanan kesehatan; tempat belajar mengajar; tempat anak bermain; tempat ibadah; angkutan umum; tempat kerja dan tempat umum. Tempat wisata termasuk dalam kategori tempat umum yang tercantum dalam Kawasan Tanpa Rokok. Pengawasan yang dilakukan oleh Satpol PP selaku petugas dalam penegak Peraturan Daerah adalah dengan melakukan sidak KTR yang telah dijadwalkan dalam waktu 3 bulan sekali dan pemasangan kamera pengawas/CCTV yang akan dipantau langsung oleh pengelola tempat wisata (wawancara dengan Satpol PPKabupaten Badung A. A Dharma Putra pada tanggal 5 Maret 2020).

Tidak hanya Satpol PP dan pengelola tempat wisata masyarakat juga mempunyai peran dalam melakukan pengawasan seperti yang tertuang dalam Peraturan Daerah Kabupaten Badung Nomor 8 Tahun 2013 tentang Kawasan Tanpa Rokok Pasal 17 Ayat 2 untuk mengingatkan setiap orang yang melanggar pada Kawasan Tanpa Rokok. Dalam melakukan pengawasan Kawasan Tanpa Rokok tentunya akan ada pelanggaran yang terjadi. Maka, saat terjadinya pelanggran perlu adanya sanksi yang diberikan demi mensukseskan Kawasan Tanpa Rokok. Sanksi berasal dari bahasa Belandayaitu Sanctie yangang artinya ancaman hukuman. Suatu alat pemaksa guna ditaatinya suatu undang-undang misalnya sanksi terhadap pelanggaran suatu undang-undang (Simorangkir dkk., 2009: 7). 
Ada 3 macam sanksi yang diterapkan di Indonesia yaitu sanksi pidana merupakan kurungan penjara sanksi perdata merupakan kewajiban untuk memenuhi suatu prestasi dan sanksi administratif dengan membayar denda. Pemerintah Daerah kabupaten Badung telah mengatur sanksi guna mensukseskan penerapan Kawasan Tanpa Rokok ini. Sanksi yang diberikan adalah sanksi pidana yaitu kurungan penjara dan sanksi administrative dengan pembayaran denda. Sanksi ini diatur dalam Peraturan Daerah Kabupaten Badung Nomor 10 Tahun 2017 Pasal 21. Untuk pengelola/pimpinan/penanggung jawab akan dikenakan kurungan paling lama 6 bulan atau denda paling banyak Rp.5.000.000 (pasal 21 ayat 1 Peraturan Daerah Kabupaten Badung nomor 10 Tahun 2017 tentang Kawasan Tanpa Rokok) sedangkan untuk masyarakat akan dikenakan kurungan paling lama 3 bulan atau denda paling banyak Rp. 1,000,000,- (Pasal 21 Ayat 1a Peraturan Daerah Kabupaten Badung Nomor 10 Tahun 2017 tentang Kawasan Tanpa Rokok).

\section{Implementasi Peraturan Daerah Kabupaten Badung Nomor 10 Tahun 2017 pada Tempat Wisata}

Penerapan adalah tindakan dari rencana yang telah disusun secara rinci dan dilakukan saat rencana selesai (Usman, 2002: 70). Satpol PP bertugas dalam penegakan Peraturan Daerah (Peraturan Pemerintah Nomor 6 Tahun 2010 tentang Satuan Polisi Pamong Praja). Dengan ini, Satpol PP mempunyai tugas dalam penegakan Peraturan Daerah tentang Kawasan Tanpa Rokok pada tempat wisata di Kabupaten Badung. Dalam penerapannya Satpol PP melakukan pembinaan dengan cara sosialisasi kepada pimpinan desa pengelola tempat wisata dan masyarakat sekitar sebagai bentuk penerapan Kawasan Tanpa Rokok. Namun Masyarakat masih belum mengetahui adanya Peraturan Daerah tentang Kawasan Tanpa Rokok ini maka penerapannya belum maksimal (wawancara dengan Satpol PP Kabupaten Badung A. A Dharma Putra pada tanggal 5 Maret 2020).

Dalam melakukan sosialisasi Satpol PP melakukan pembinaan kepada pimpinan desa pengelola tempat wisata dan masyarakat sekitar tentang tempat wisata yang termasuk dalam kawasan tanpa rokok. Setelah Satpol PP melakukan pembinaan pengelola tempat wisata wajib memasang tanda/Sticker Kawasan Tanpa Rokok agar masyarakat yang tidak mengetahui dapat mengetahui bahwa seluruh area tersebut termasuk Kawasan Tanpa Rokok Adanya pemasangan tanda/Sticker tentang Kawasan Tanpa Rokok menandakan jika penerapan Kawasan Tanpa Rokok itu sudah dilakukan namun adanya sebuah larangan untuk tidak merokok sembarangan pada tempat wisata membuat pemerintah daerah juga harus memberikan solusi kepada para perokok dimana seharusnya tempat untuk merokok. Dalam Peraturan Daerah Kabupaten Badung tentang Kawasan Tanpa Rokok Nomor 10 tahun 2017 Pasal 12 Ayat 1 mengatakan bahwa Pengelola Pimpinan dan/atau Penanggung jawab tempat kerja tempat umum dan tempat lainnya wajib menyediakan tempat khusus merokok. Kriteria tempat khusus merokok diatur dalam Pasal 12 Ayat 2 yaitu: ruang terbuka atau ruang yang berhubungan langsung dengan udara luar; jauh dari pintu masuk dan keluar; jauh dari tempat orang berlalu-lalang.

Saat penerapannya Satpol PP perlu bekerja sama dengan pengelola tempat wisata agar Kawasan Tanpa rokok pada tempat wisata ini dapat berjalan dengan semestinya. Tidak hanya memasang larangan untuk tidak merokok pengelola tempat wisata juga harus memberikan tempat khusus merokok sebagai solusi. Perlunya pemasangan tanda/Sticker dengan jelas agar memudahkan masyarakat untuk tidak merokok diarea Kawasan Tanpa Rokok dan mencari tempat khusus merokok yang telah disediakan oleh pengelola tempat wisata setempat dengan ini akan mengurangi terjadi pelanggaran. Menurut Bapak Nengah Mahaputra selaku pengunjungdi Museum Pasifika Nusa Dua Bali (wawancara pada 8 Februari 2020) Bapak Nengah tidak mengetahui bahwa tempat wisata termasuk dalam Kawasan Tanpa Rokok setelah diperhatikan lingkungan sekitarnya bahwa ada tanda larangan untuk merokok.

Dengan ini penegakan Peraturan Daerah telah di terapkan di tempat wisata dengan memberikan tanda larangan untuk merokok hanya saja masayarakat sekitar belum mengetahui Peraturan tentang kawasan Tanpa Rokok. Tidak semua masyarakat mengetahui isi peraturan daerah tentang kawasan tanpa rokok seperti tempat apa saja yang dilarang dan dimana seharusnya seseorang dapat merokok diarea Kawasan Tanpa Rokok. Semenjak diberlakukannya Peraturan Daerah Provinsi Bali tentang Kawasan Tanpa Rokok Pemerintah Kabupaten Badung menindaklanjutinya dengan berbagai kegiatan pembinaan dan pengawasan. 
Menurut Soekanto salah satu penghambat dalam proses penegakan hukum adalah faktor hukum; faktor aparat penegak hukum; faktor sarana atau fasilitas; faktor masyarakat dan faktor budaya (Soekanto, 2011). Dalam penegakan Kawasan Tanpa Rokok di Kabupaten Badung pada tempat wisata yang menjadi faktor penghambat adalah masyarakat yang belum mengetahui peraturan daerah tentang kawasan tanpa rokok (wawancara dengan Satpol PP Kabupaten Badung A. A Dharma Putra pada Tanggal 5 Maret 2020).

Masyarakat menjadi faktor penghambat pelaksanaan Penegakan Hukum. Hal ini dikarenakan tidak semua masyarakat mengetahui Perda tentang KTR apalagi pada tempat wisata. Ketidak tahuan masyarakat menjadi faktor penghambat yang membuat masih adanya pelanggaran yang terjadi pada tempat wisata. Wisatawan yang berkunjung tidak hanya berasal dari pulau bali tetapi ada juga yang berasal dari luar bali bahkan luar negeri. Hanya sedikit masyarakat yang mengetahui tentang kawasan tanpa rokok sehingga perlunya penandaan agar memudahkan siapapun yang berada pada tempat wisata untuk mengetahui bahwa tidak boleh merokok di semua tempat dan diarahkan kemana seharusnya seseorang jika ingin merokok.

\section{SIMPULAN DAN SARAN}

\section{Simpulan}

Dalam Pengaturan Kawasan Tanpa Rokok menurut Peraturan Pemerintah No. 6 Tahun 2010 Pasal 1 Angka 8 bahwa Satpol PP selaku penegak Peraturan Daerah melakukan pengawasan seperti yang telah termuat dalam Peraturan Daerah Kabupaten Badung Nomor 8 Tahun 2013 Pasal 18 dan masyarakat juga berperan dalam melakukan pengawasan sesuai Peraturan Daerah Kabupaten Badung Nomor 8 Tahun 2013 Pasal 17. Dalam melakukan pengawasan tentunya akan ada pelanggaran yang dilakukan demi mensukseskan Kawasan Tanpa Rokok ini telah diatur sanksi dalam Peraturan Daerah Kabupaten Badung Nomor 10 Tahun 2017 Pasal 21.

Implementasi Kawasan Tanpa Rokok pada tempat wisata sudah dilaksanakan oleh Satpol PP selaku petugas dalam penegakan Peraturan daerah dan dibantu oleh pengelola tempat wisata dalam mengawasi dan memberikan sarana dan prasarana yang dibutuhkan. Adapun faktor penghambat dalam penerapan kawasan tanpa rokok ini ialah masyarakat yang belum mengetahui tentang kawasan tanpa rokok pada tempat wisata dikarenakan masyarakat yang mengunjungi tempat wisata di kabupaten badung tidak hanya berdomisili di Kabupaten Badung tempat lahirnya Peraturan Daerah ini namun juga berasal dari luar bali bahkan Luar Negeri.

\section{Saran}

Satpol PP apabila dalam melakukan pengawasan ditemukan pelanggaran yang dilakukan oleh pengelola tempat wisata atau masyarakat untuk menerapkan sanksi tegas seperti yang tercantum dalam Peraturan Daerah Kabupaten Badung Nomor 10 Tahun 2017 Pasal 21. Pengelola tempat wisata agar secara tegas dapat menegur pelanggaran yang terjadi diarea tempat wisata sehingga masyarakat sendiri juga mengetahui bahwa tempat wisata termasuk dalam Kawasan Tanpa Rokok.

\section{DAFTAR PUSTAKA}

Azkha, N. (2013). Studi Efektivitas Penerapan Kebijakan Perda Kota Tentang Kawasan Tanpa Rokok (KTR) dalam Upaya Menurunkan Perokok Aktif di Sumatera Barat Tahun 2013. Jurnal Kebijakan Kesehatan Indonesia, 02(04), 171-179.

Juanita. (2012). Kebijakan Kawasan Tanpa Rokok: Peluang dan Hambatan. Jurnal Kebijakan Kesehatan Indonesia, 1(2), 112-119.

Marchel, Y. A., Indraswari, R., \& Handayani, N. (2019). Implementasi Kawasan tanpa Rokok Sebagai Pencegahan Merokok Pada Remaja Awal. Jurnal Peomkes: The Indonesian Journal of Health Promotion and Health Education, 7(2), 144-155.

Priyangga, S. W. (2017). Penerapan Sanksi Pidana dalam Peraturan Daerah Kota Metro No.4 Tahun 2014 tentang Kawasan Tanpa Rokok. Poenale: Jurnal Bagian Hukum Pidana, 5(4).

Simorangkir, J. C. T., Erwin, R. T., \& Prasetyo, J. T. (2009). Kamus Hukum. Sinar Grafika. 
Soekanto, S. (2011). Faktor-Faktor yang Mempengaruhi Penegakan Hukum. Rajawali Pers.

Solicha, R. A. (2012). Tingkat Pengetahuan dan Sikap Pengunjung di Lingkungan RSUP Dr. Kariadi tentang Kawasan Tanpa Rokok: Studi Kasus di RSUP Dr. Kariadi Semarang (Vol. 1, Issue 1).

Suryani, D., \& Suhartini, E. (2018). Regulation of Non-Smoking Areas in Local Government Regulation. Jurnal Hukum De'Rechtsstaat, 4(2), 105-113.

Usman, N. (2002). Konteks Implementasi Berbasis Kurikulum. PT. Raja Grafindo Persada.

\section{Undang-Undang}

Undang-Undang Nomor 36 Tahun 2009 tentang Kesehatan

Peraturan Daerah ProvinsiBali Nomor 10 Tahun 2011

Peraturan Daerah Kabupaten Badung Nomor 8 tahun 2013

Peraturan Daerah Kabupaten Badung Nomor 10 Tahun 2017 